\title{
Ensaio sobre os Estudos de Defesa e a Comunidade que os Pratica
}

\author{
Essay on Defense Studies \\ and its Practicing Community
}

Rev. Bra. Est. Def. v. 2, nº 2, jul./dez. 2015, p. 29-39

ISSN 2358-3932

\section{HÉCTOR LUIS SAINT-PIERRE}

Dois esclarecimentos iniciais: em primeiro lugar, diferentemente dos que me precederam na mesa "A Epistemologia dos Estudos de Defesa", não sou ninguém e portanto não preciso dizer que não falo em representação de algo ou que falo em nome próprio: só posso falar em nome próprio. Em segundo lugar, concordando com a lógica de Antonio Jorge Ramalho, que assegura que as apresentações começaram da melhor para a pior, e sendo que sou o último orador, não esperem grande coisa do tenho para dizer.

Mas começaria por um breve, e consequentemente supérfluo, esclarecimento sobre as chamadas "ciências duras" e as outras tentando afastar alguns mitos. As ciências naturais não são mais objetivas que as sociais e estas não são mais subjetivas que a física por ter como objeto a ação social, sempre sujeita à intencionalidade. Como afirmava Max Weber, o que leva um cientista a tentar desenvolver uma fórmula e não outra qualquer é uma questão de fé. Ele também fala da dificuldade de compatibilizar essa fé, necessária para interessar ao cientista no seu objeto, com a necessária objetividade pretendida pela ciência. Em que consiste a "objetividade" da ciência se somos obrigados a partir, tanto na seleção da área epistêmica, quanto no recorte do objeto de estudo, de um âmbito puramente subjetivo? Mais do que um âmbito meramente subjetivo, a "subjetividade" aqui significa aquela fé que nos move a fazer o que estamos fazendo, a pesquisar o nosso objeto de estudo.

A fé na "realidade" que estamos analisando é, em última instância, a própria formulação da realidade e esta se apoia integralmente naquela. Desde Kant está claro que não há possibilidade de comprovar a existência de algo fora de mim, fora do que é produzido pelo meu entendimento, do

Héctor Luis Saint-Pierre - Doutor em Filosofia Política (Unicamp) e professor de Relações Internacionais (UNESP). E-mail: hector.sp@uol.com.br 
fenômeno. Daquilo fora de nós que postulamos como estando na origem do fenômeno, o que Kant chamou Noúmeno (do grego vooú $\mu \varepsilon v o v)$, nada podemos dizer. $\mathrm{O}$ objeto do conhecimento é apenas o que aparece depois de ter passado pelo filtro das categorias do entendimento, do meu aparelho cognitivo. Mas a exigência científica do princípio de "objetividade" se resolve na corroboração intersubjetiva. É dizer: minha subjetividade é corroborada por outras subjetividades e, resignadamente, isso é tudo o que pode fornecer alguma objetividade, como a pretendida pela ciência. Claro, essa intersubjetividade não atende a referência a qualquer subjetividade, mas trata-se de uma intersubjetividade qualificada. Aquelas subjetividades que fornecerão intersubjetivamente a pretendida "objetividade" científica são subjetividades qualificadas. A qualificação das subjetividades que podem fornecer objetividade ao conhecimento é definida pela intersubjetividade conhecida como "comunidade epistêmica", isto é, uma comunidade de subjetividade cujas estruturas de entendimento foram formadas pela transmissão das subjetividades que constituem a "comunidade científica”.

Com essa qualificação das subjetividades, entramos na consideração do que chamamos "Comunidade epistêmica da Defesa", que não é o mesmo que "Comunidade de Defesa", que é outra comunidade formada por cientistas, assessores e atores da Defesa. A primeira é composta apenas por aqueles cuja atividade principal é a ciência, no nosso caso nacional, é a Associação Brasileira de Estudos de Defesa (ABED). Os que integram esta comunidade estudam, desde diferentes espaços epistêmicos, a Defesa. Nisso reside a dignidade epistêmica da Defesa: no fato de ser objeto de nosso conhecimento, da nossa reflexão, da nossa vocação científica. Nós, que integramos esta comunidade, não nos consideramos "defensólogos"; somos historiadores, sociólogos, filósofos, cientistas políticos, especialistas em Relações Internacionais, etc. Nossa consistência científica nos é dada pela nossa formação numa área específica do saber, pela nossa pertinência a uma área epistêmica específica, mas o que nos reúne é um específico objeto de estudo em comum: a Defesa.

Essa é a nossa consideração científica. A comunidade científica nos outorga o título de doutores, nos reconhece como tais. Fazemos parte dessa comunidade, que por sua vez é custódia da ciência. A ciência é custodiada, e essa custódia é exercida pelos cientistas que são reconhecidos enquanto tal pela comunidade científica. São os cientistas que têm a obrigação de cercear o acesso à comunidade científica, que controlam o rito de passagem, pelo qual um estudioso passa a ser considerado um cientista por essa comunidade. Em outras palavras, quando um pós-graduando pretende ser doutor, deve passar por uma série de ritos e testes de reconhecimentos pelos seus futuros pares. Assim, para se doutorar numa área do saber, 
ele aceita se submeter às condições e ritos de passagem predeterminadas pela comunidade científica que custodia esse saber. Quando considerado aprovado como candidato, se apresentará ante uma banca, um jurado formado por cientistas minimamente doutores, reconhecidos pela comunidade científica, que determinará se o candidato reúne as condições que essa mesma comunidade definiu como necessárias para ser outorgado o título de doutor nessa área do saber. Portanto, esse grupo de cientistas não apenas se considera justo custódia desse saber específico, mas também se considera justo avaliador das condições para ingressar nessa sua comunidade científica.

A ciência, como toda a atividade humana, é uma atividade política. Do ponto de vista político, interessa questionar por quem decide ou influencia nas decisões que afetam essa comunidade científica que constrói, divulga e custodia a ciência. Por isso, uma pergunta digna de ser formulada, eu que não pretendo responder aqui, é: A quem interessa defender a criação de uma área epistêmica específica de Defesa? Para quê criar uma área epistêmica de Defesa? Essas são as perguntas que devemos ter em mente quando se discute a criação de uma nova área do saber.

Nós temos o nosso reconhecimento científico em cada uma de nossas áreas (História, Sociologia, Ciências Políticas, Antropologia, Ciências Sociais em Geral, Relações Internacionais, com suas teorias e metodologias específicas), mas também nos reconhecemos mutuamente nas associações científicas às que nos associamos, tanto na ABED [Associação Brasileira de Estudos de Defesa], quanto na ABRI [Associação Brasileira de Relações Internacionais]. Nelas nos reconhecemos não apenas como cientistas, mas como cientistas que tem seu objeto específico de reflexão na Defesa; nessas associações nos reconhecemos mutuamente em nossa dignidade científica, assim como reconhecemos coletivamente a dignidade de nossos trabalhos. Para isso não precisamos contar com uma área epistêmica específica de Defesa, o que sim precisamos é de um Comitê Cientifico específico para o tema para realizar as avaliações de projetos no CNPq. Ter contado com um comitê científico, ainda que por pouco tempo, foi extremamente importante para o desenvolvimento e consolidação de nossa comunidade epistêmica de Defesa. E isso é muito importante, por quê? Porque como toda atividade, a ciência é uma atividade política e, em alguns casos, pesam mais os critérios políticos que os científicos na hora de decidir se uma solicitação de apoio financeiro procede ou não, se um pedido para publicação em mérito científico ou não, se um artigo para ser apresentado em congresso científico é meritório ou não.

O preconceito é um fenômeno político-sociológico bastante observado nas comunidades, tanto de praxe quanto científicas: se, por um lado, 
alguns militares olham com certo desdém aos estudiosos de Defesa, por considerar que esse tema é exclusivo deles, por outro lado, devemos reconhecer que os Estudos de Defesa ainda sofrem de forte resistência para serem reconhecidos na sua dignidade epistêmica dentro das universidades. Ainda somos obrigados a ouvir, entre alguns historiadores, que "a História Militar e da Guerra é coisa de 'milico' e não tem nada a ver com História”. Assim, não é difícil imaginar que, por exemplo, um trabalho de História Militar submetido ao $\mathrm{CNPq}$, para solicitar recursos para ser apresentado em congresso, seja recusado ante a alegação de que "não se trata de um trabalho propriamente historiográfico”, isto é, não é reconhecido pelos pares como História. Em Ciência Política e Relações Internacionais a dificuldade reside em que ambas pertencem ao mesmo Comitê da Capes e a qualisização de revistas e livros acadêmicos ainda é feita por uma e a mesma comissão, sem definir critérios de qualis específico para as publicações da área de Relações Internacionais.

Um dos passos históricos na construção da comunidade epistêmica da Defesa que não se mencionou aqui foi a consolidação do grupo de trabalho GT "Forças Armadas, Estado e Sociedade”, da Associação Nacional de Pós-Graduação e Pesquisa em Ciências Sociais ANPOCS. Esse grupo não apenas foi um importante antecedente da nossa comunidade como também da integração com a área de Relações Internacionais. Naquele momento na ANPOCS funcionava também o GT de Relações Internacionais e Política Externa, conhecido como GRIPE. Mas para esse congresso não tinham conseguido o número mínimo de trabalhos apresentados e não conseguiram aprovar o GRIPE, mas nós sim conseguimos aprovar o GT Forças Armadas, Estado e Sociedade, que já gozava de excelente prestígio na ANPOCS. Como coordenador deste GT, convidei os colegas do GRIPE a apresentarem seus trabalhos no nosso GT, já que considerava que muitos dos resultados de pesquisas do GRIPE poderiam perfeitamente ser acomodadas no nosso GT, pois tratavam de temas internacionais que também eram tratados no nosso GT, no qual tratávamos de temas internacionais. Depois de tudo, não há fenômeno mais dramático na história nem tema mas crucial nas Relações Internacionais do que a Guerra (o intento de evitar ou humanizar as guerras está na origem dos primeiros cursos de RI no período de entre guerras).

Não há nada mais dramático do que temas decorrentes dos conflitos armados nas Relações Internacionais, não há nada mais dramático do que a guerra. O primeiro livro de história, no sentido moderno, foi $A$ Guerra do Peloponeso, de Tucidides. Trata-se, além de fundar metodologicamente a área de história no sentido moderno, de um livro de Relações Internacionais, no sentido duro do termo, e é um texto que fala da guerra. 
Mas naquele momento de consolidação do GT Forças Armadas, Estado e Sociedade na ANPOCS, nas Relações Internacionais ainda prevalecia um certo preconceito contra quem estudava Defesa. Claro, considerava-se que os Estudos de Defesa eram relativos ao interior do Estado, que refletiam sobre a estrutura do Estado, sobre os militares como atores, sobre processos de transição à democracia, relações civis-militares, controle civil sobre os militares, mas desde as Relações Internacionais considerava-se que nosso estudo não guardava nenhuma relação com os seus temas específicos de estudo. $\mathrm{Na}$ verdade, naquele momento as Relações Internacionais estavam pensando sua identidade epistêmica e procurando sua autonomia com relação à Ciência Política e se aproximarem do nosso grupo poderia comprometer sua identidade e postergar essa autonomia. Mas a história da nossa comunidade de Estudos de Defesa passou por todos esses aspectos e momentos, que foram muito bem narrados pelos que me precederam e que me poupam de fazer outros comentários.

Nalgum momento daquela história, Julián González Guyen, um apreciado colega e amigo uruguaio especialista da nossa área, convidou-me a participar como comentarista de um trabalho que, com sua equipe, tinham feito sobre a Política de Defesa no Uruguai, analisando a questão de política de defesa dos uruguaios. O que estava no centro do profundo e longo trabalho era a tese, muito propagada naquele momento, de que a forma de controlar os militares e garantir a subordinação militar era por médio do aperto no orçamento da Defesa: cortando ou fechando a torneira do orçamento seria possível controlar os militares. Achei algo errado nessa tese que me incomodava e montei meu comentário, imaginando que seria uma reunião puramente acadêmica, já que fora marcada na Faculdade de Direito da Universidade da República. Daí minha surpresa quando soube que também participavam da reunião o Ministro da Defesa e os comandantes. Não obstante o cenário tivesse mudado radicalmente, eu já havia preparado minha exposição e decidi apresentá-la, já que refletia o que pensava: quando se trata de um ator armado, ou se confia ou não se confia, não há situação intermediária. Se não se confia se desarma imediatamente, pois não se pode governar com um ator armado não confiável. Agora, no caso de confiar nesse ator, do que se trata quando pensamos na Defesa, que tipo de armamento, doutrina, preparo e formação precisa-se para cumprir da melhor maneira possível a missão que o Estado atribua para ele. Não importa, do ponto de vista acadêmico, quanto custa manter armado e preparado o instrumento da Defesa, o que importa é a destinação desse instrumento. $\mathrm{O}$ que importa na discussão, como acadêmicos que pretendem contribuir com a Defesa, é qual o objeto e destinação do monopólio da força do Estado e qual o meio, doutrina e preparo adequados para essa destinação. O Estado 
não conta com Forças Armadas apenas para o desfile militar, as Forças Armadas cumprem um papel definido constitucionalmente, e para cumprir esse papel deve dispor das condições necessárias para seu emprego.

A reflexão sobre a destinação do monopólio legítimo da força por parte do Estado conduz a decidir sobre o lócus epistêmico dessa reflexão, que não diz apenas sobre a relação entre as Forças Armadas e o Estado, mas também, e principalmente, sobre a relação entre esse Estado e outros Estados com os quais convive num ambiente imprevisível, ante o qual, como diria Raymond Aron, se impõe o cálculo estratégico. Essa constatação sobre a perspectiva epistemológica dos Estudos de Defesa levou-me a escrever um brevíssimo artigo, cujo título diz muito mais do que o seu conteúdo: “A 'revolução copernicana' nos Estudos de Defesa”. Notei que estávamos analisando as questões relativas à Defesa como uma inflexão interior ao Estado: controle militar, condução, transição, etc. Estávamos perdendo nas nossas considerações o aspecto estratégico que supõe a projeção desse Estado num mundo incerto. Existe a Defesa como estrutura institucional do Estado, porque este se encontra alojado num mundo imprevisível porque não há nele uma normativa que obrigue a todos os Estados que nele se encontram. Nesse mundo não há uma lei (nem um monopólio da força por detrás dela) que impeça que um Estado ataque a outro por qualquer motivo que considere vital. Por isso, cada unidade política precisa calcular as capacidades dos seus vizinhos e a probabilidade de que algum deles se encaminhe pelo caminho de uma aventura militar que coloque em risco a autonomia da sua decisão, daí que se imponha o cálculo estratégico como forma inteligentemente precavida de sobreviver num mundo incerto onde o "outro" pode se constituir numa ameaça.

Por isso, naquele artigo defendo que o lugar epistêmico específico para estudar a Defesa são as Relações Internacionais, e nisso concordo com a exposição do meu colega, Samuel Alves Soares, em que a ontologia do objeto dos Estudos de Defesa é externa, sua referência é o outro, o “ $x \boldsymbol{e}$ nos", o estrangeiro. Daí que também concorde com ele em que trata-se de uma patologia estatal a introdução do conceito de "inimigo" para o âmbito interno, o que significa tratar o compatriota como xenos, o que permite eliminá-lo. A América do Sul viveu esse drama durante a Guerra Fria e a incorporação da tristemente lembrada Doutrina da Segurança Nacional, DSN. Com ela se levou a questão das fronteiras ao âmbito ideológico e se considerou "inimigo" e passível de sequestro, tortura e desaparecimento forçado aqueles que professassem uma ideologia considerada desestabilizadora para o regime imposto. Com o traçado de fronteiras internas à sociedade, questões que deveriam ser resolvidas politicamente, dissolvidas agonalmente pela despolitização estatal, foram consideradas dentro da 
DSN como "ameaças" e combatidas pelas Forças Armadas, que deveriam ser empregadas exclusivamente (pelo sua caraterística de letalidade) para as ameaças externas.

Estes fatos perturbaram durante décadas a realização normal dos Estudos da Guerra e de Defesa que, no caso do Brasil, se iniciam com a irrupção golpista contra a ordem institucional em 1964. Por isso, eu começaria a história da nossa área diretamente com a transição política à democracia que fornecerá a matéria para os primeiros estudos da nossa área. Notadamente e não por acaso, os primeiros estudos da área que começaram a congregar nossa comunidade epistêmica serão estudos sobre os processos de transição.

Considero que há uma diferença substantiva entre "tema" epistêmico e "área” epistêmica. A área epistêmica é definida por uma conjugação de métodos específicos aceitos como corretos, isto é, uma metodologia, uma ou várias teorias específicas que comporiam o arcabouço teórico, e um objeto específico que ancora a disciplina. Os Estudos de Defesa contam como elemento comum apenas o seu objeto específico de estudo, as metodologias correspondem às áreas epistêmicas, a partir das quais se aborda esse objeto, e o mesmo pode ser dito em relação às teorias. Isso não significa que uma "indignidade epistêmica", muito pelo contrário, isso representa uma riqueza epistêmica. Não ter método específico e teorias específicas nos permite ter o diálogo interdisciplinar que fortalece e enriquece a perspectiva dos Estudos de Defesa da nossa comunidade. Essa é a riqueza da nossa comunidade epistêmica que devemos preservar. Se formos pelo caminho da feudalização dos Estudos de Defesa, pretendendo constituí-los em área epistêmica específica, terminaremos criando odiosas fronteiras dentro da nossa comunidade. Logo mais os historiadores de guerra serão discriminados porque seus estudos não são da área epistêmica dos Estudos de Defesa; logo os estudos sociológicos sobre os militares serão discriminados por não serem da área; passaremos a discriminar os antropólogos, os psicólogos, e assim por diante. Mas por que discriminaremos? Porque a ciência é uma atividade política e o que está em jogo é a disputa por verba, por orçamento para a pesquisa, por um lugar na assessoria das financiadoras de pesquisa, pelo poder de determinar quem pode publicar numa revista de Estudos de Defesa, pelo poder de definir quem pode participar dos congressos da área, etc. Não se faz pesquisa sem orçamento que pague bolsas, viagens, encontros, publicações, e essa disputa pelo orçamento é que está trazendo essas questões da Defesa como área epistêmica.

"Ciências Militares" são aquelas ciências que informam ao militar para melhor desempenhar sua função específica, que é se preparar para a guerra. Ciências Militares, como uma unidade de conhecimento, não constitui 
uma ciência. O militar na sua função específica não faz ciência, assim como o construtor de uma nave espacial tampouco o faz. Não quero dizer que não existam militares cientistas ou militares intelectuais, porque os há e alguns conheço, sendo muito bons e sofisticados intelectuais. Mas quem colocar a sua vida ao serviço da ciência não vai bater nas portas da Escola Preparatória de Cadetes do Exército (EsPECEx), ele se dirigirá aos portões da universidade, do mesmo modo que aquele cuja vocação seja pela carreira militar, não acudirá a uma universidade civil, mas irá à preparatória. Uma vocação não é nem mais nobre nem mais digna que a outra; a nobreza e dignidade de uma vocação reside na entrega e seriedade com que se assume.

Com efeito, mais do que de atividades, quando falamos do indivíduo que a exerce, se trata de vocações. $\mathrm{O}$ militar tem uma função específica e o cientista outra, e acredito que isso resulta meridianamente claro para ambos. Aceitar esta consideração não significa pensar que um cientista não possa ir à guerra, seria ignorar aqueles heróis acadêmicos que morreram em combate como soldados cumprindo seu dever/direito cívico de defender a pátria. Do mesmo modo que seria injusto e inverídico não reconhecer o valor intelectual de muitos oficiais dedicados à reflexão teórica e científica sobre o homem, a sociedade e a guerra. Quem dos aqui presentes não estudou com entusiasmo e respeito os escritos de Jomini, de Clausewitz, de Lidell Hart, de Beaufre e tantos outros? Eles eram militares de profissão e sobretudo de vocação, verdadeiros e tenazes combatentes, mas que não se furtaram de refletir sistemática e metodicamente sobre o mesmo objeto de reflexão que nos congrega.

Mas o que devemos reconhecer é que, simplesmente, para ascender em sua carreira militar, um oficial não precisa escrever um livro, publicar um artigo em revista qualis, participar em congressos científicos e orientar alunos. No caso do cientista, publicar é fundamental, embora dificilmente seria prejudicado na sua carreira acadêmica por decisões ou ações erradas tomadas em combate, coisa que para o militar sim. São duas vocações que exigem de quem por elas se enveredem diferentes desafios, mas desafios que o consumirão diuturnamente com exclusividade.

As Ciências Militares informam ao militar sobre conhecimentos que possam lhe ser úteis na sua profissão específica, mas esse conjunto de saberes não tem como objetivo formar um cientista, mas auxiliar um militar. Uma coisa é que o militar precise de noções de química, ou saber alguns conceitos de física, que saiba de balística e todas essas ciências que contribuem com o militar, aprimorando sua prática como militar. Outra coisa é o estudo da Física por aquele que pretende dedicar sua vida a essa área específica do saber humano, que pesquisará e ministrará aulas de Física, 
participará de congressos de Física e formará outros físicos. Para estudar Física profissionalmente, o estudante deve estar liberado de fazer guarda, ordem fechado, treinamento de tiro e salto de paraquedas. Esse profissional deve estar estudando as leis e teorias da física desde a manhã até a noite, como se faz em qualquer disciplina acadêmica, como se faz na profissão militar o que deve ser feito para ser um militar. A atividade do cientista é claramente diferente da atividade do militar, nem mais nem menos nobre, apenas diferente.

Como cientistas que temos como objeto os Estudos de Defesa e como patriotas brasileiros, devemos nos debruçar sobre os conceitos e teorias correntes para explicar o nosso objeto, que é a Defesa. Muitos desses conceitos e teorias são importados de maneira acrítica e implementados sem critério, sem levar em conta as particularidades e necessidades nacionais da Defesa. Assim como com a implantação de teorias econômicas formuladas nas metrópoles se estabelece a dependência econômica, aceitando esses conceitos e teorias estratégicas se importa também a dependência epistêmica sobre a que se baseia a dependência estratégica. Não tenho lugar aqui para desenvolver isto, apenas quero enfatizar a importância de pensar com autonomia e levando em conta as características nacionais, tanto os conceitos quanto as teorias que nutrem os Estudos de Defesa. Não estou pregando a ignorância de todos os conceitos e teorias que circulam pelo mundo (muitos dos quais formulados especificamente para consolidar a dependência estratégica da periferia), mas sim analisar profundamente o que está por detrás desses conceitos e teorias, procurando desconstruir o discurso da dependência para reconstruir nosso próprio discurso estratégico, para buscar a reflexão que defenda a autonomia e a decisão soberana. Acho que não tenho muito mais o que dizer, na realidade creio que esgotei o tema no capítulo "Pensamento em Defesa no Brasil em perspectiva filosófica e histórica", presente no livro Pensamento Brasileiro em Defesa, de Alvaro Dias Monteiro, Érica Winand e Luiz Rogério Franco Goldroni.

Nossa área está crescendo, com trabalhos em maior quantidade e de melhor qualidade científica. Nas nossas associações (ABED e ABRI), onde apresentam suas pesquisas tanto civis quanto militares, não há nenhum tipo de discriminação, com a única condição de que seja comprovada a qualidade científica do trabalho. Estamos com uma ABED consistente e forte. $\mathrm{Na}$ ABRI, a área temática de Segurança Internacional, Estudos Estratégicos e Política de Defesa é uma das áreas mais concorrida, com um número crescente de trabalhos, tanto quantitativamente quanto qualitativamente.

Então, tentando resumir minha apresentação: para os antigos gregos a ciência, que eles chamavam epistéme, se encontrava entre outros dois tipos de conhecimento, a doxa e o nous, que poderíamos traduzir como a opinião 
e o conhecimento intelectivo. Para eles, o que definia a epistéme era se tratar de um conhecimento verdadeiro ou também um conhecimento pelas causas, conheço cientificamente quando conheço pelas causas ou quando meu conhecimento é verdadeiro. Hoje, depois das críticas epistemológicas, mudou o conceito de ciência e a verdade já não faz parte da definição, pois não há forma lógica de verificar uma teoria. Por isso, nos vemos obrigados a ressignificar o conceito de ciência e alguns epistemólogos concluem que a ciência só é definível como uma certa atividade humana que persiste através dos tempos e das revoluções científicas. Por isso, como diria Raymond Aron, ainda sabendo que logicamente a verdade é inatingível, temos a obrigação ética de persegui-la, não obstante cientificamente não acreditemos nela. Assim como devemos eticamente continuar perseguindo a paz, ainda sabendo que ela é impossível. Se a ciência a que nos devotamos é uma atividade, ela deve ser regida por uma ética: ainda que ciência resignadamente nos informe da sua impossibilidade, como incansáveis peregrinos em busca da fonte da felicidade eterna, devemos guiar eticamente nossa atividade orientados pela paz e pela verdade, ainda que não acreditemos nelas. 


\section{NOTAS}

1. Foi o Grupo de Trabalho número 8 do $30^{\circ}$ Encontro Anual da ANPOCS, o qual ocorreu em 2006, na cidade de Caxambu/MG.

2. Ver artigo completo em: <https://www.academia.edu/3768143/A_ REVOLU\%C3\%87\%C3\%83O_COPERNICANA_NOS_ESTUDOS_ DA_DEFESA $>$.

\section{ENSAIO SOBRE OS ESTUDOS DE DEFESA E A COMUNIDADE QUE OS PRATICA}

\section{RESUMO}

Consideramos a ciência como uma atividade humana e, em enquanto tal, uma atividade política. Com esse critério, analisamos os Estudos de Defesa como a atividade principal desenvolvida pelos membros da comunidade epistêmica de Defesa. Fazemos uma breve referência histórica da sua evolução e da composição sociológica da comunidade que a pratica. Defendemos que a Defesa não constitui uma área epistêmica, mas um digno objeto epistêmico abordado desde diferentes dimensões epistêmicas.

Palavras chave: Defesa; Estudos de Defesa; Epistemologia da Defesa; Comunidade Epistêmica de Defesa.

\section{ABSTRACT}

We consider science as a human activity, and as such a political activity. As from this criterion, we analyze the Defense Studies as the main activity carried out by members of the epistemic community of Defense. We make a brief historical reference of its evolution and sociological composition of the community that practices it. We argue that Defense is not an epistemic area itself, but a worthy epistemic object approached from different epistemic dimensions.

Key-words: Defense; Defense Studies; Defense Epistemology; Defense Epistemic Community. 